\title{
Analysis of the complexity of the multimeric structure of factor VIII related antigen/von Willebrand protein using a modified electrophoretic technique
}

\author{
MS ENAYAT, FGH HILL
}

From the Department of Haematology, The Children's Hospital, Ladywood, Birmingham B16 $8 E T$

SUMMARY A method for multimeric analysis of factor VIII related antigen/von Willebrand protein is described. By modifying an existing method the technique has been simplified and optimised so that the different molecular forms of factor VIII related antigen and their triplet structure can be visualised. Clear differences can be seen between patterns in normals and type $\mathrm{II}_{\mathrm{A}}$ von Willebrand's disease variants in that the latter lack high and intermediate multimers and also have a different configuration to the triplet pattern in the lower molecular weight multimers. Differences in triplet pattern can also be seen in different type $\mathrm{II}_{\mathrm{A}}$ patients. The advantages and further application of this method for investigating the molecular defect in von Willebrand's disease are discussed.

A high molecular weight protein, factor VIII related antigen/von Willebrand protein (VIIIR:AG) is associated with factor VIII procoagulent protein (VIII:C) ${ }^{1-4}$ The structural complexity of VIIIR:AG has been studied with electrophoresis using large pore polyacrylamide, ${ }^{45}$ or agarose and acrylamide gels. $^{6-9}$. Early studies suggested that normal VIIIR:AG consists of an aggregating series of polydispersed oligomers. ${ }^{4}$ Similar studies of this protein in patients with von Willebrand's disease have been done and classifications proposed. ${ }^{10-12}$ Electrophoresis of VIIIR:AG on a sodium dodecyl sulphate (SDS) glyoxyl agarose gel ${ }^{13}$ and a commercially available rehydratable SDS agarose gel $^{14}$ have allowed the identification of high, medium and low molecular weight oligomers. Ruggeri and Zimmerman have referred to these analyses as multimeric and have proposed a classification of subtypes of von Willebrand's disease. ${ }^{15}$ They subsequently reported another method of SDS gel electrophoresis using a discontinuous buffer system providing increased resolution. ${ }^{16}$ We report further modification of this technique which provides even more precise resolution of the VIIIR:AG multimeric bands.

\section{Material and methods}

\section{REAGENTS}

Unless otherwise stated these were as described by Ruggeri and Zimmerman, ${ }^{16}$ and the chemical reag-

Accepted for publication 23 February 1983 ents used were supplied by either BDH Chemicals Ltd or Sigma Chemical Company.

Rabbit anti-human factor VIII immunoglobulin (IgG fraction) was supplied by DAKO Immunoglobulins $\mathrm{a} / \mathrm{s}$, Mercia-Brocades Ltd. and after labelling with ${ }^{125}$ I from Radiochemicals Centre, Amersham, used for the final autoradiography.

\section{IgM}

IgM purified from a patient with IgM myeloma was used as a molecular marker of known molecular weight.

\section{PATIENTS AND CONTROLS}

Venous blood was obtained by venepuncture from normal adult men and selected severe type I and type $\mathrm{II}_{\mathrm{A}}$ von Willebrand's disease patients. Nine parts of blood were added to one part of 0.11 molar trisodium citrate. Platelet poor plasma was prepared by centrifugation at $1500 \mathrm{~g}$ for $15 \mathrm{~min}$ at $4^{\circ} \mathrm{C}$. Separated plasma was snap frozen at $-20^{\circ} \mathrm{C}$ and thawed at $37^{\circ} \mathrm{C}$ before use. Patients studied were $\mathrm{LW}$ type $\mathrm{I}$ or severe classical vWD (VIII:C, VIIIR:AG and VIIIR:Wf all zero); $\mathrm{HW}$ type $\mathrm{II}_{\mathrm{A}}$ or variant vWD (VIII:C $0.4 \mathrm{U} / \mathrm{ml}$, VIIIR:AG $0.63 \mathrm{U} / \mathrm{ml}$ and VIIIR:Wf 0.05 U/ml.) and CB (VIII:C $0.54 \mathrm{U} / \mathrm{ml}$, VIIIR:AG $0.86 \mathrm{U} / \mathrm{ml}$ and VIIIR:Wf $0.05 \mathrm{U} / \mathrm{ml}$.).

SDS GEL ELECTROPHORESIS

The method of VIIIR:AG multimeric analysis 
described by Ruggeri and Zimmerman ${ }^{16}$ has been modified by altering the electrophoretic conditions (current and time of electrophoresis), by increasing the gel size and by using a labelled commercial antihuman VIIIR:AG antibody (IgG) instead of an affinity purified antibody for the autoradiography.

\section{Gel preparation}

Agarose gels (1.4\% and $2 \%)$ and an agarose $(0.8 \%)$ and acrylamide $(2.5 \%$ with $5 \%$ cross linking) gel were used. A large gel to take 13 samples was prepared by pouring $25 \mathrm{ml}$ of hot unpolymerised running gel in a sandwich set $(17 \times 12 \times 0.1 \mathrm{~cm})$ made of a piece of gel bond film covering one glass plate and separated from a second glass plate by a $1 \mathrm{~mm}$ thick U-shaped plastic spacer. The two glass plates are held together with binder clips. After the running gel has set, the top glass plate is removed and a $3-5 \mathrm{~mm}$ strip from the top of the gel is cut away and discarded. The top glass plate is reclamped into its original position and $5 \mathrm{ml}$ of stacking gel poured above the running gel and left to set for one hour at $4^{\circ} \mathrm{C}$. Thirteen rectangular sample wells $(8 \times 2 \mathrm{~mm})$ were cut in the stacking gel at $5 \mathrm{~mm}$ intervals and 10 $\mathrm{mm}$ from the interface with the running gel.

\section{Electrophoretic conditions}

Different conditions were tested (see Results) in a Pharmacia FEB-3000 flat bed electrophoretic tank. Optimal electrophoresis was achieved with a constant initial current of $1.9 \mathrm{~mA} / \mathrm{cm}$ from a Pharmacia ECP $3000 / 150$ power supply until the samples had migrated from the wells. The empty wells were filled with stacking gel and electrophoresis. A Pharmacia volt-hour integrator $\mathrm{mA} / \mathrm{cm}$ ). Electrophoresis is stopped when the tracking dye has moved $10 \mathrm{~cm}$ from the wells. This is usually achieved after $8 \mathrm{~h}$. However, if more convenient, similar results could be obtained if a current of $1.2 \mathrm{~mA} / \mathrm{cm}$ is used during overnight electrophoresis. A Pharmacia volt-hour integrator (VH-l) coupled to the power supply registered 2000-2500 volthours for each run. After electrophoresis the gels are fixed washed and dried as described by Ruggeri and Zimmerman ${ }^{16}$ prior to autoradiography.

In the thirteenth well purified IgM is run as a molecular weight marker. This strip of dried gel is cut away and stained with Coomasie brilliant blue.

\section{AUTORADIOGRAPHY}

The dried plates are incubated overnight in a commercial rabbit antihuman VIIIR:AG immunoglobulin labelled with ${ }^{125} \mathrm{I}$ by the Chlorine gas method ${ }^{17}$ at specific activity of $10-20 \mathrm{mCi}$ per $\mathrm{mg}$ protein and diluted in $60 \mathrm{ml}$ of veronal buffer to $1 \times 10^{6} \mathrm{cpm} / \mathrm{ml}$. After incubation the gels are washed thoroughly in saline followed by distilled water and then dried. Autoradiograph plates are produced using a Dupont Cronex 4 film in a cassette fitted with Dupont Quanta II intensifying screen. The plates have to be kept at $-70^{\circ} \mathrm{C}$ for $2-3$ days to allow clear definition of the bands.

\section{Results}

Clear differences could be observed (Fig. 1) between the multimeric patterns of normal plasma and that from a patient with type $\mathrm{II}_{\mathrm{A}}$ von Willebrand's disease obtained after electrophoresis on $1.4 \%$ and $2 \%$ agarose gels and $0.8 \%$ agarose- $2.5 \%$ acrylamide gel. On all gels, from above downwards high, intermediate and low molecular weight multimer bands can be seen in normal, while for the $\mathrm{II}_{\mathrm{A}}$ patients the high and intermediate molecular weight multimers are absent. With severe vWD patient (LW) no bands are seen. Qualitative differences, however, are seen on the different gels. Electrophoresis on $1.4 \%$ agarose gave the most poorly defined multimer pattern while that on $2 \%$ agarose was clearer with a wider spread and a further high molecular band (band 8) seen clearly. Definition and length of spread was best on $0.8 \%$ agarose$2.5 \%$ acrylamide gel.

The effect of changing electrophoretic conditions to obtain further resolution into the clearest multimeric pattern (Figs. 1, 2 and 3) is summarised in the Table. The clearest resolution was obtained with a starting current of $1.9 \mathrm{~mA}$ followed by $2.5 \mathrm{~mA}$ after sample migration from the well (see Methods) for $8 \mathrm{~h}$ and whereas bands 1-6 had appeared as single bands they could now be seen to be more complex with a dense central band flanked on either side by a fainter band. With this technique a final comparison was made between normal plasma and a type $\mathrm{II}_{\mathrm{A}}$ variant. As well as the $\mathrm{II}_{\mathrm{A}}$ patient lacking the high molecular weight multimers, there are qualitative differences in the triplet pattern of the lowest two triplets (band 1 and 2).

In the normal plasmas (see Figs. 3 and 4) the triplet pattern is of a central band with minor less densely stained bands on either side and designated as $a$ and $b$. In the multimeric analysis of the type $\mathrm{II}_{\mathrm{A}}$ patients studied here (Fig. 4) bands 1 to 4 are clearly seen. However, band 4 is weaker than band 4 in a normal plasma while band 3 is of similar intensity to the normal band 3 but the $3 \mathrm{~b}$ band is much stronger in the $\mathrm{II}_{\mathrm{A}}$ patients. Band 2 is dense and the $\mathrm{a}$ and $\mathrm{b}$ bands are denser than in the normal. Band 1 is also stronger in the $\mathrm{II}_{\mathrm{A}}$ patients than in normals and the a and $b$ bands are also more concentrated. Differences in the strength of the $1 \mathrm{~b}$ band are seen between patients HW and CB (see Fig. 4). 


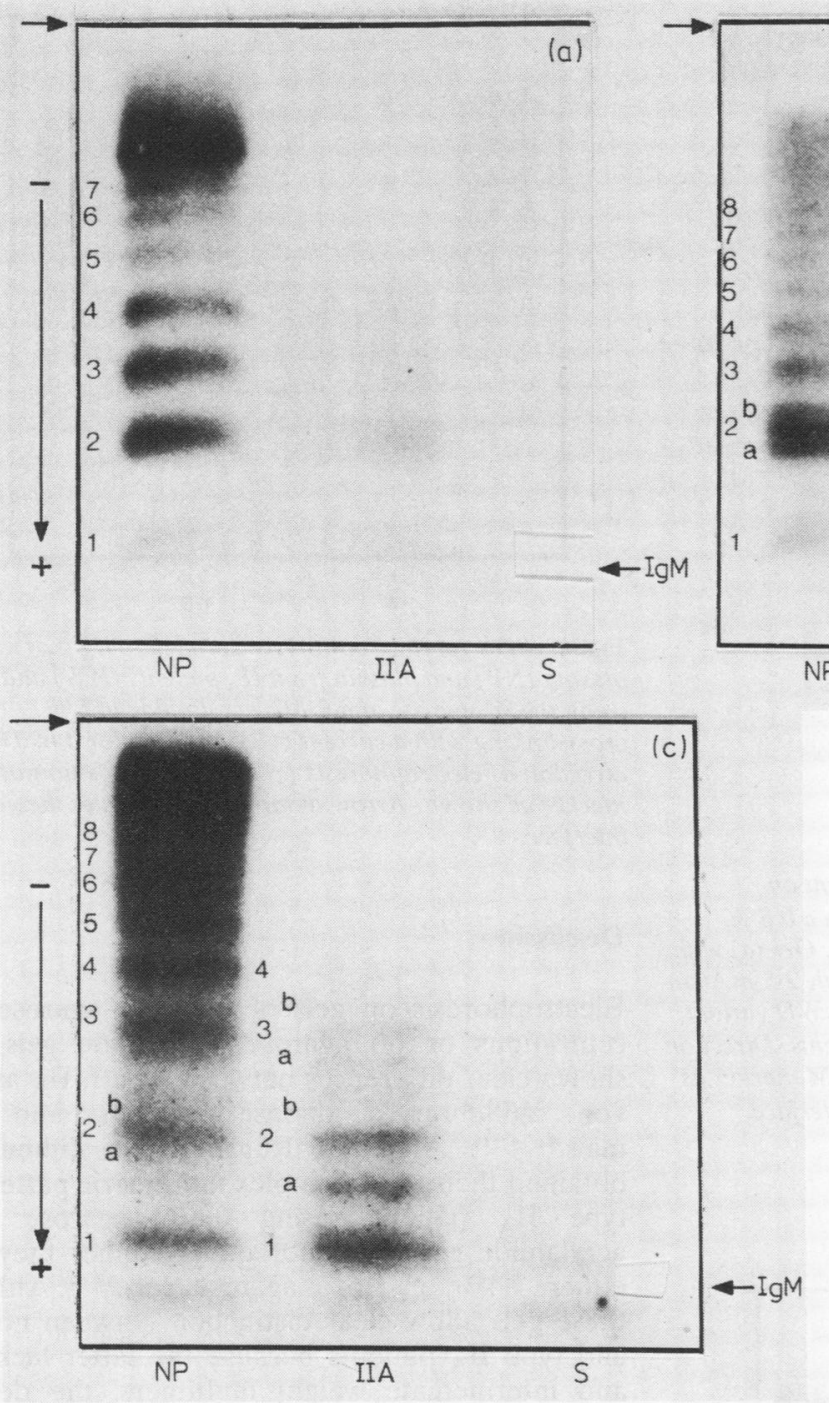

Fig. 1 Comparison of the quality of multimer separation by SDS gel electrophoresis using different agarose concentrations and agarose with acrylamide. In each plate from left to right is seen the pattern for plasma from normal control (NP), type $I I_{A} v W D$ variant $\left(I I_{A}\right)$ and a patient with severe $v W D(S)$. Direction of electrophoresis $(-\rightarrow+)$ and position of IgM marker as shown. Arrow at top of gel indicates the gel interface. The composition of the gel used is as follows: (a) $1.4 \%$ agarose; (b) $2.0 \%$ agarose; (c) $0.8 \%$ agarose, $2.5 \%$ acrylamide.

Effect of different electrophoretic conditions on clarity of multimer separation

\begin{tabular}{|c|c|c|c|}
\hline \multicolumn{2}{|l|}{ Current in $\mathrm{mA} / \mathrm{cm}$} & \multirow{2}{*}{$\begin{array}{l}\text { Time (h) of } \\
\text { electrophoresis }\end{array}$} & \multirow{2}{*}{$\begin{array}{l}\text { Quality of multimer separation } \\
\text { with normal plasma }\end{array}$} \\
\hline $\begin{array}{l}\text { Prior to migration } \\
\text { from well }\end{array}$ & $\begin{array}{l}\text { After migration } \\
\text { from well }\end{array}$ & & \\
\hline $\begin{array}{l}0.78 \\
1.6\end{array}$ & $\begin{array}{l}1 \\
2\end{array}$ & $\begin{array}{l}6 \\
6\end{array}$ & $\begin{array}{l}\text { Poor separation } \\
\text { Resolution into six bands plus unresolved high } \\
\text { molecular weight region. No triplet structure } \\
\text { to bands (see Fig. } 2 \text { gel (a)). }\end{array}$ \\
\hline $1 \cdot 9$ & $2 \cdot 5$ & 6 & $\begin{array}{l}\text { Eight clear bands plus a smaller unresolved high } \\
\text { molecular weight region. Bands } 1 \text { and } 2 \text { showing } \\
\text { triplet appearance but not as three distinct bands } \\
\text { (see Fig. } 2 \text { gel (b)). }\end{array}$ \\
\hline 1.9 & $2 \cdot 5$ & 8 & $\begin{array}{l}\text { Eight to twelve clear bands and small unresolved area } \\
\text { of highest molecular weight multimers. Bands } 1-6 \\
\text { showing triplet pattern. Doublet and single band } \\
\text { anodal to band also seen clearly (see Fig. } 3 \text { ). }\end{array}$ \\
\hline
\end{tabular}




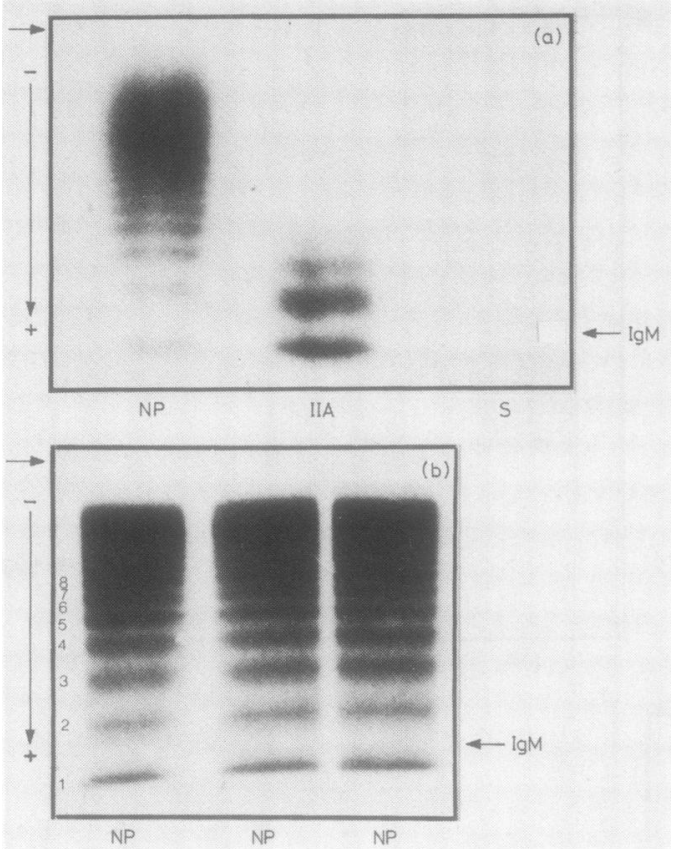

Fig. 2 Effect of different electrophoretic current on resolution of multimeric bands of factor VIII in a $0.8 \%$ agarose $12.5 \%$ acrylamide at $5 \%$ cross-linking. Gel (a) with a constant current of $2 \mathrm{~mA} / \mathrm{cm}$, and gel (b) with $2.5 \mathrm{~mA} / \mathrm{cm}$ for $6 \mathrm{~h} . \mathrm{NP}=$ normal plasma, $I I_{A}=$ type $I I_{A} v W D$ variant and $S=$ plasma from a severe $v W D(L W)$ patients. Direction of electrophoresis $(-\rightarrow+)$ and position of IgM marker as shown. Arrow at top of gel indicates the gel interface.

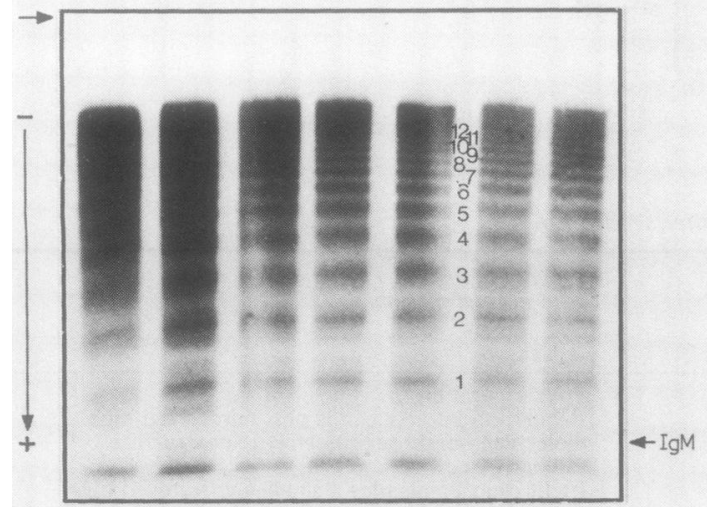

Fig. 3 SDS gel electrophoresis of normal plasma in $0.8 \%$ agarose $12.5 \%$ acrylamide at $5 \%$ cross-linking run for $8 \mathrm{~h}$ at $2.5 \mathrm{~mA} / \mathrm{cm}$. Direction of electrophoresis $(-\rightarrow+)$ and position of IgM marker as shown. Gel interface is indicated by arrow at top of gel.

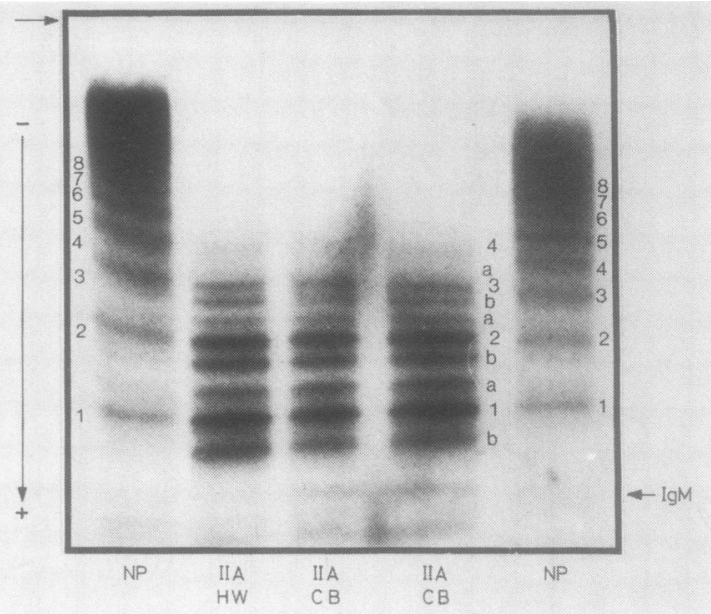

Fig. 4 SDS gel electrophoresis from left to right of normal plasma $(N P)$ and plasma from $I_{A}$ patients $(H W)$ and $(C B)$, using $0.8 \%$ agarose and $2.5 \%$ acrylamide at $5 \%$ cross-linking with a current at $2.5 \mathrm{~mA} / \mathrm{cm}$ for $8 \mathrm{~h}$. The direction of electrophoresis $(-\rightarrow+)$ and position of IgM marker as shown. Arrow at top of gel indicates the gel interface.

\section{Discussion}

Electrophoresis on gels of different agarose concentrations or on agarose acrylamide gels have shown clear differences between type $\mathrm{I} \mathrm{II}_{\mathrm{A}}$ and $\mathrm{II}_{\mathrm{B}}$ von Willebrand's disease patients and normals. ${ }^{111^{14-16}}$ Although Ruggeri and Zimmerman obtained their most complex multimeric pattern for type $\mathrm{II}_{\mathrm{A}}$ patients using $0.8 \%$ agarose $2.5 \%$ acrylamide gels, ${ }^{16}$ in subsequent studies they used either $1.4 \%$ or $1.6 \%$ agarose gels. ${ }^{18} 19$ Although these gels allow clear distinction between normals and type $\mathrm{II}_{\mathrm{A}}$ patients because the latter lack high and intermediate weight multimers, the detailed complexity of the triplet configuration of the lower molecular weight multimers is not shown. In a recent report, a patient has been described who, in addition to lacking the high molecular weight multimers, has an absent triplet pattern and a repeating doublet pattern. None of the bands seen in these patients has the same mobility as bands seen in normals or previously described von Willebrand's disease patients. These patients have been classified as type $\mathrm{II}_{\mathrm{C}}{ }^{20}$

We have shown here how by optimising electrophoretic conditions it is possible to provide increasing resolution revealing a very complex multimeric pattern in normals and von Willebrand's disease variants. This better resolution shows that two different $\mathrm{II}_{\mathrm{A}}$ variants $(\mathrm{CB}, \mathrm{HW})$ not only lack the 
high and intermediate multimers but that the configuration of the triplet pattern of the lower two bands also differs from that seen in normals and in each other.

Application of this refined technique may, therefore, allow further reclassification of von Willebrand's disease patients and by use in family studies allow the identification of inherited asymptomatic multimer defects and how these may interact to produce symptomatic bleeding disorders.

This work was supported by a grant from the Endowment Research Fund, Birmingham Central Health District. We thank Dr Bradwell, IDRU, University of Birmingham for the purified IgM molecular weight marker and $\mathrm{Mr} \mathrm{W}$ Robinson, Women's Hospital, Birmingham, for technical assistance in radiolabelling the antisera used.

\section{References}

' Hershgold EJ, Davison AM, Janszen ME. Isolation and some chemical properties of human factor VIII (antihaemophilic factor). J Lab Clin Med 1971;77:185-205.

${ }^{2}$ Marchesi SL, Shulman NR, Gralnick HR. Studies on the purification and characterization of human factor VIII. J Clin Invest 1972;51:2151-61.

${ }^{3}$ Legaz ME, Schmer G, Counts RB, Davie EW. Isolation and characterization of human factor VIII (antihaemophilic factor). J Biol Chem 1973;248:3946-55.

${ }^{4}$ van Mourik JA, Bouma BN, La Bruyere WT, de Graaf S, Mochtar IA. Factor VIII, A series of homologous oligomers and complex of two proteins. Thrombosis Res 1974;4:155-64.

${ }^{5}$ Girma JP, Pietu G. Lavergne JM, Meyer D, Larrieu MJ. Abnormal antigenic reactivity of factor VIII/von Willebrand factor subunit in variants of von Willebrand's disease. J Lab Clin Med 1982;99:481-94.

- Fass DN, Knutson GJ, Bowie EJW. Porcine Willebrand factor: a population of multimers. J Lab Clin Med 1978;91:307-20.

' Beck EA, Tranqui-Point L, Chapel A, Perret BA, Furlan M, Hudry-Clergeon G, Suscillon M. Studies on Factor VIII related protein. I. Ultrastructural and electrophoretic heterogeneity of human Factor VIII-related protein. Biochem Biophys Acta 1979;578:155-63.

Serret BA, Furlan M, Beck EA. Studies on Factor VIII-related protein. II. Estimation of molecular size differences between Factor VIII oligomers. Biochem Biophys Acta 1979;578:164-74.

9 Wienstein M, Deykin D. Comparison of Factor VIII-related von Willebrand Factor proteins prepared from human cryoprecipitate and Factor VIII concentrate. Blood 1979;53:1095-105.

${ }^{10}$ Meyer D, Obert B, Pietu G, Lavergne JM, Zimmerman TS. Multimetric structure of factor VIII/von Willebrand factor in von Willebrand's disease. J Lab Clin Med 1980;95:590-602.

${ }^{11}$ Ruggeri ZM, Pareti FI, Mannucci PM, Ciavarella N, Zimmerman TS. Heightened interaction between platelets and Factor VIII/ von Willebrand Factor in a new subtype of von Willebrand's disease. $N$ Engl J Med 1980;302:1047-51.

12 Nachman RL, Jaffe EA, Miller C, Brown WT. Structural analysis of Factor VIII antigen in von Willebrand disease. Proc Natl Acad Sci USA 1980;77:6832-6.

${ }^{13}$ Hoyer LW, Shainoff JR. Factor VIII-related protein circulates in normal human plasma as high molecular weight multimers. Blood 1980;55:1056-9.

${ }^{14}$ Ruggeri ZM, Zimmerman TS. Variant von Willebrand's disease. Characterizations of two subtypes by analysis of multimeric composition of Factor VIII/von Willebrand Factor in plasma and platelets. $J$ Clin Invest 1980;65:1318-25.

is Ruggeri ZM, Zimmerman TS. Classification of variant von Willebrand's disease subtypes by analysis of functional characteristics and multimeric composition of Factor VIII/von Willebrand Factor. Ann NY Acad Sci 1981;370:205-9.

${ }^{16}$ Ruggeri ZM, Zimmerman TS. The complex multimeric composition of Factor VIII/von Willebrand Factor. Blood 1981; 57:1140-3.

${ }^{17}$ Butt WR. The iodination of follicle-stimulating and other hormones for radioimmunoassay. $J$ Endocr 1972;55:453-4.

${ }^{18}$ Ruggeri ZM, Mannucci PM, Lombardi R, Federici AB, Zimmerman TS. Multimeric Composition of Factor VIII/von Willebrand Factor following administration of DDAVP: Implication for pathophysiology and therapy of von Willebrand's disease subtypes. Blood 1982;59:1272-8.

19 Ruggeri ZM, Lombardi R, Gatti L, Bader R, Valsecchi C, Zimmerman TS. Type II $_{B}$ von Willebrand's disease: Differential clearance of endogenous versus transfused large multimer von Willebrand Factor. Blood 1982;60:1453-6.

${ }^{20}$ Battle J, Ruggeri ZM, Holmberg L, Nilsson IM, Zimmerman TS. The triplet structure of von Willebrand factor multimers: Abnormalities in a new variant of von Willebrand's disease (type $\mathrm{II}_{\mathrm{C}}$ ). Abstract, Symposium on Factor VIII/von Willebrand factor. San Diego, October 1982:26.

Requests for reprints to: Dr FGH Hill, Department of Haematology, The Children's Hospital, Ladywood, Birmingham B16 8ET, England. 